\title{
DSC characterization of rabbit corneas treated with Stryphnodendron adstringens (Mart.) Coville extracts
}

\author{
Luiz Guilherme Ito da Cruz ${ }^{1,2}$ - Gabriela de Andrade Moraes ${ }^{3}$. \\ Regina Freitas Nogueira ${ }^{2}$ - Andreia de Araujo Morandim-Giannetti ${ }^{3}$. \\ Patrícia Alessandra Bersanetti ${ }^{4}$
}

Received: 20 May 2016/Accepted: 9 January 2017/Published online: 30 January 2017

(C) Akadémiai Kiadó, Budapest, Hungary 2017

\begin{abstract}
Keratoconus is an eye ectasia that affects the cornea causing distortion of vision. Corneal crosslinking promoted by riboflavin photo-stimulated at $365 \mathrm{~nm}$ is a treatment used successfully to block the keratoconus progression. In this study, we characterize rabbit corneas subjected to enhanced crosslinking using different vegetable extracts prepared from Stryphnodendron adstringens (Mart.) Coville bark by differential scanning calorimetry. The extracts tested in this study were: aqueous, ketonic, ethanolic, ethyl acetate and hydroalcoholic, which revealed high levels of polyphenols, such as proanthocyanidins. The corneas, obtained from the slaughter rabbits, were divided into groups: control (consisting of untreated corneal samples) and $S$. adstringens, where the samples were subjected to $4 \%$ vegetable extracts for $2 \mathrm{~h}$. The DSC profiles of the corneas were obtained in nitrogen atmosphere. The results showed that temperature and enthalpy of denaturation of the corneal samples treated with $S$. adstringens were higher than the control group. The control group presents temperature and enthalpy values of $59.8 \pm 1.1^{\circ} \mathrm{C}$ and
\end{abstract}

This work was presented in X CBRATEC (004A).

Patrícia Alessandra Bersanetti

bersanetti@unifesp.br

1 Departamento de Oftalmologia e Ciências Visuais, Escola Paulista de Medicina, Universidade Federal de São Paulo, São Paulo, SP, Brazil

2 Departamento de Informática em Saúde, Escola Paulista de Medicina, Universidade Federal de São Paulo, São Paulo, SP, Brazil

3 Departamento de Engenharia Química, Centro Universitário da FEI, São Bernardo do Campo, SP, Brazil

4 Departamento de Bioquímica, Escola Paulista de Medicina, Universidade Federal de São Paulo, São Paulo, SP, Brazil
$24.6 \pm 2.7 \mathrm{~J} \mathrm{~g}^{-1}$, respectively. After crosslinking with ketone extract, the values were $90.1 \pm 1.1^{\circ} \mathrm{C}$ and $39.9 \pm 2.7 \mathrm{~J} \mathrm{~g}^{-1}$. These results show that $S$. adstringens is efficient to increment the crosslinking level of the corneas.

Keywords Cornea $\cdot$ Crosslinking $\cdot$ Polyphenols · Stryphnodendron adstringens

\section{Introduction}

Several possibilities and materials are currently being investigated to provide new treatments for eye diseases. It is known that corneal diseases such as keratoconus, trauma and ulceration affect many people and can lead to blindness or corneal transplants [1-3].

The cornea is a transparent avascular connective tissue that acts as the primary barrier against infectious and structural deformations, providing a proper anterior refractive surface for the eye. With respect to the corneal structure, the stroma represents a great part of its thickness, being composed mainly of type I collagen [4]. Its clarity is the result of many factors, including the space between the lamellae and deturgescence of its matrix and cellular components. The diameter of the collagen fibrils and the interfibrillar spacing are responsible for adequate transparency and refractive power of the cornea $[5,6]$.

Keratoconus is an ectasia that affects the curvature of the cornea that takes a conical shape leading to decreased vision power and quality of life of patients. In advanced stages, it may be necessary to perform a corneal transplant [7]. In this context, it becomes essential to be aware of the composition and possibilities of regeneration of the corneal structure.

In recent years, the corneal crosslinking (CXL) procedure has been effective in blocking keratoconus 
progression, for stiffening the cornea with an increase in mechanical strength [8-10]. In this treatment, riboflavin stimulated by ultraviolet radiation at $365 \mathrm{~nm}$ is used. Riboflavin is responsible for generating singlet oxygen, which causes the binding of adjacent collagen fibrils through covalent bonds [11].

Therefore, studies have shown that CXL induces an increase in the elastic modulus [12] and resistance to the enzymatic degradation of the corneas [13]. However, this treatment can promote apoptosis and necrosis of endothelial cells of the corneas, as demonstrated in rabbit eyes after $24 \mathrm{~h}$ of treatment with an UVA irradiation dose of $0.65 \mathrm{~J} \mathrm{~cm}^{-2}$ [14]. In addition, other studies showed that UVA radiation was detrimental to the keratinocytes [15]. Consequently, the search for molecules that promote CXL without ultraviolet light stimulation is appropriate.

In this context, it has been shown that crosslink in collagen can be induced by natural compounds such as genipin [16] and proanthocyanidins (PA) [17, 18]. PA are polyphenolic compounds, thus having various hydroxyl groups and being found in various vegetables and fruits, as cocoa, grape, S. adstringens, etc. [19] (Fig. 1).

The crosslinking promotes the loss of hydration water from collagen fibers with a subsequent increase in the denaturation temperature of the material [20]. Thus, the modification of the tissue structure and the crosslinking efficiency can be analyzed from the denaturation profile of corneas by differential scanning calorimetry.

As the stem bark of $S$. adstringens contains different polyphenols compounds such as tannin (10-37\%), flavan3-ols, proanthocyanidins and prorobinetinidins [21, 22], this study verified the influence of stem extracts of this plant in the crosslinking of the rabbit corneas by DSC.

\section{Materials and methods}

This work was approved by the (Number 7534220114) from the São Paulo Federal University (UNIFESP, Brazil). The S. adstringens (Mart.) Coville bark was acquired in the Municipal Market of São Paulo (São Paulo, Brazil). The plant name has been checked on http://www.theplantlist. org (access on November 18, 2016).

\section{Preparation of the extracts}

The extracts of the $S$. adstringens bark (aqueous, ethanolic and acetone/water 7:3) were prepared by solvent extraction for up to 7 days, followed by concentration on a rotary evaporator Fisatom 558 (São Paulo, Brazil) and drying at room temperature. The dry aqueous extract was dissolved in ethanol/water (1:1) and subjected to liquid-liquid extraction with hexane and ethyl acetate, respectively.

\section{Crosslinking of the rabbit corneas}

The enucleated rabbit eyes purchased from a slaughterhouse (Granja dos Ipês, Mairinque, Brazil) were submitted to removal of the hydrophobic epithelium and trepanned to obtain corneas. The control group consisted of untreated corneas. In the corneas that received treatment, the samples were immersed in a $4 \%$ solution of the dried extracts (aqueous, ethanolic or ketonic) or the fractions derived from the aqueous extract (ethyl acetate or hydroalcoholic extract) for $2 \mathrm{~h}$.

\section{Characterization of the corneas by DSC}

Initially, the control and corneas subjected to treatment with the different $S$. adstringens extracts (aqueous, ethanolic, acetone/water 7:3, ethyl acetate or hydroalcoholic) were cut in samples with $2-3 \mathrm{mg}$, that were hermetically sealed in aluminum crucibles to prevent water evaporation. The DSC analyses were performed in a calorimetric cell Shimadzu DSC-60 (Kyoto, Japan) in the range of $25-110{ }^{\circ} \mathrm{C}$ using a heating rate of $10{ }^{\circ} \mathrm{C} \mathrm{min}{ }^{-1}$

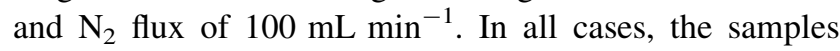
were reheated to confirm denaturation. Prior to the analyses, the DSC cell was calibrated with indium $\left(T_{\text {fusão }}=\right.$ $156.4{ }^{\circ} \mathrm{C}$ and $\Delta H_{\text {fusão }}=28.5 \mathrm{~J} \mathrm{~g}^{-1}$ ).

The curves of heat flux versus temperature obtained for all samples were used to calculate the denaturing temperature and the enthalpy. These values were used to compare the effect of corneal treatment with the different $S$. adstringens extracts.

For the ketone extract, the measures of the temperature and enthalpy of denaturation were performed in triplicate, and the results were analyzed by t-test.

The enthalpy values were corrected discounting the water weight of the samples determined in a Shimadzu MOC-63U moisture analyzer (Kyoto, Japan).

\section{Results and discussion}

The thermal characterizations by DSC were performed to corneas of the groups: control and corneas treated with $S$. adstringens extracts (aqueous, acetone/water, ethanolic, ethyl acetate or hydroalcoholic) (Fig. 2). DSC curves showed endothermic events corresponding to the denaturation of the treated and control samples. In all DSC analyses, the endothermic peaks appeared only in the first heating due to irreversible denaturation of corneas. 
<smiles></smiles><smiles>C=CC(=C)[C@H]1Oc2cc(O)cc(O)c2[C@@H](c2c(O)cc3c(c2O)C[C@@H](O)[C@@H](c2ccc(O)c(O)c2)O3)[C@H]1O</smiles>

3<smiles>Oc1cc(O)c2c(c1)O[C@@]1(c3ccc(O)c(O)c3)O[C@]2(c2c(O)cc(O)c3c2OC(c2ccc(O)c(O)c2)[C@@H](O)C3)[C@H]1O</smiles>

4

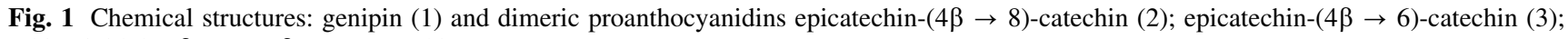
robinetinidol-( $2 \beta \rightarrow 7,4 \beta \rightarrow 8)$-catechin (4)

All extracts prepared from the $S$. adstringens, except the hexanic extract, provided a pronounced increase in denaturation temperature of the corneas, compared to the control group. This temperature increase can be attributed to the dehydration of collagen fibrils [20], as a result of crosslinking.

The increase in denaturation enthalpy values was also observed in all cases which can be associated with the 


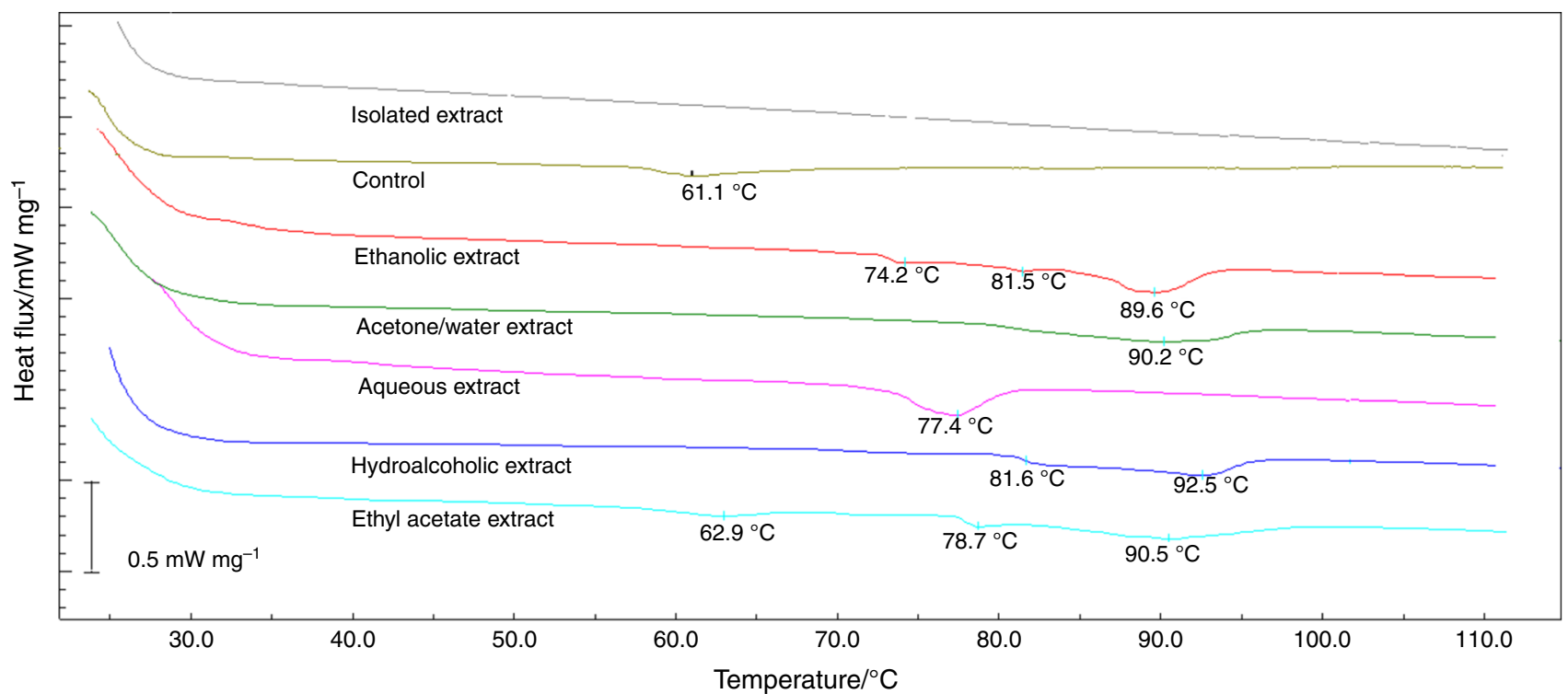

Fig. 2 DSC curve of cornea control and submitted to crosslinking with $4 \%$ solution of $S$. adstringens aqueous, ketone, ethanolic extracts and ethyl acetate or hydroalcoholic fraction, for $2 \mathrm{~h}$. The DSC curve of the isolated ketone extract is also showed

formation of stronger intermolecular interactions between stromal molecules as collagens and polyphenols. The structural specificity of the polyphenolic compounds allows hydrogen interactions as well as hydrophobic interactions [23]. The role of the $-\mathrm{COOH}$ group of the gallic acid in its binding to collagen is clearly established using various solution NMR measurements [24].

It was also observed that some extracts produced a DSC profile with multiple peaks resulting from different types of crosslinks or forms of collagen helix folding. The heterogeneous distribution of crosslinks may be caused by slow diffusion of polyphenols in the cornea [25].

The extract obtained using acetone/water led to the greatest increase in denaturation temperature. The DSC analysis of the effect of this extract in cornea was performed in triplicate. Analyzing the results in Table 1, a significant increase is evident in denaturation temperature $(p=0.000005)$ and enthalpy $(p=0.002)$ after crosslinking with the ketone extract of $S$. adstringens $\left(T=90.1 \pm 1.1{ }^{\circ} \mathrm{C} ; \Delta H=39.9 \pm\right.$ $\left.2.7 \mathrm{~J} \mathrm{~g}^{-1}\right)$ compared to the control group $(T=59.8 \pm$ $1.1{ }^{\circ} \mathrm{C}, \Delta H=24.6 \pm 2.7 \mathrm{~J} \mathrm{~g}^{-1}$ ).

Studies demonstrated the efficiency of the proanthocyanidins (a flavonoid class) in the crosslinking of the dental matrix [26] and porcine heart valves [27]. Slusarewicz et al. [28] comparing the efficiency of seven compounds in collagen crosslinking observed that the PA were very efficient and reacted rapidly with the tissue. In addition, Bersanetti et al. [29] showed that the açaí extract is efficient to promote an increase in the denaturation temperature and enthalpy of rabbit corneas.

As the $S$. adstringens extracts contain different compounds, such as flavonoids and phenolic acids, in this
Table 1 Values of the denaturation enthalpy/ $\mathrm{J} \mathrm{g}^{-1}(H)$ and temperature $/{ }^{\circ} \mathrm{C}(T)$ of the rabbit corneas of the control group and treated with a $4 \%$ solution of the $S$. adstringens ketone extract for $2 \mathrm{~h}$

\begin{tabular}{llllll}
\hline Sample & \multicolumn{2}{l}{ Control } & & \multicolumn{2}{c}{ S. adstringens } \\
\cline { 2 - 3 } & $T$ & & & $T$ & $H$ \\
\hline 1 & 61.1 & 27.6 & & 91.1 & 38.7 \\
2 & 59.3 & 23.5 & 89.0 & 38.0 \\
3 & 59.0 & 22.5 & 90.2 & 42.9 \\
Mean & 59.8 & 24.6 & & 90.1 & 39.9 \\
SD & 1.1 & 2.7 & & 1.1 & 2.7 \\
\hline
\end{tabular}

study one or more molecules may be responsible for crosslinking. Therefore, other characterizations and studies will be conducted in order to identify the compounds responsible for this activity and also to analyze the cytotoxicity and biocompatibility, using ketone extract of S. adstringens.

\section{Conclusions}

The $S$. adstringens stem bark extracts promoted the formation of crosslinks in rabbit corneas, which was demonstrated by the significant increase in denaturation temperature compared to the corneas of the control group. Further corneal crosslinking studies will be conducted after purification of the plant extract.

Acknowledgements This work was supported by the grant \#2013/ 20857-3 from São Paulo Research Foundation (FAPESP) and CNPq. 


\section{References}

1. Luo $\mathrm{H}$, Lu Y, Wu T, Zhang M, Zhang Y, Jin Y. Construction of tissue-engineered cornea composed of amniotic epithelial cells and acellular porcine cornea for treating corneal alkali burn. Biomaterials. 2013;4:6748-59.

2. Wang J, Gao C, Zhang Y, Wan Y. Preparation and in vitro characterization of BC/PVA hydrogel composite for its potential use as artificial cornea biomaterial. Mater Sci Eng C. 2010;30:214-8.

3. Fagerholm P, Lagali NS, Ong JA, Merrett K, Jackson WB, Polarek JW, Suuronen EJ, Liu Y, Brunette I, Griffith M. Stable corneal regeneration four years after implantation of a cellfree recombinant human collagen scaffold. Biomaterials. 2014;35:2420-7.

4. Maurice DM. The structure and transparency of the cornea. J Physiol. 1957;136(2):263-86.

5. DelMonte DW, Kim T. Anatomy and physiology of the cornea (Review). J Cataract Refr Surg. 2011;37:588-98.

6. Komai $\mathrm{Y}$, Ushikif $\mathrm{T}$. The three-dimensional organization of collagen fibrils in the human cornea and sclera. Invest Ophth Vis Sci. 1991;32(8):2244-58.

7. Rabinowitz YS. Keratoconus. Surv Ophthalmol. 1998;42(4): 297-319.

8. Raiskup F, Theuring A, Pillunat LE, Spoerl E. Corneal collagen crosslinking with riboflavin and ultraviolet-A light in progressive keratoconus: ten-year results. J Cataract Refract Surg. 2015;41:41-6.

9. Spoerl E, Huhle M, Seiler T. Induction of cross-links in corneal tissue. Exp Eye Res. 1998;66(1):97-103.

10. Wollensak G, Spoerl E, Seiler T. Riboflavin/ultraviolet-A-induced collagen crosslinking for the treatment of keratoconus. Am J Ophthalmol. 2003;135(5):620-7.

11. Zhang Y, Conrad AH, Conrad GW. Effects of ultraviolet-a and riboflavin on the interaction of collagen and proteoglycans during corneal cross-linking. J Biol Chem. 2011;286(15):13011-22.

12. Wollensak G, Spoerl E, Seiler T. Stress-strain measurements of human and porcine corneas after riboflavin-ultraviolet-A-induced cross-linking. J Cataract Refr Surg. 2003;29(9):1780.

13. Spoerl E, Wollensak G, Seiler T. Increased resistance of crosslinked cornea against enzymatic digestion. Curr Eye Res. 2004;29(1):35-40.

14. Wollensak G, Spoerl E, Wilsch M, Seiler T. Endothelial cell damage after riboflavin-ultraviolet-A treatment in the rabbit. J Cataract Refr Surg. 2003;29(9):1786-90.

15. Spoerl E, Mrochen M, Sliney D, Trokel S, Seiler T. Safety of UVA-riboflavin cross-linking of the cornea. Cornea. 2007;26(4): 385-9.
16. Avila MY, Navia JL. Effect of genipin collagen crosslinking on porcine corneas. J Cataract Refr Surg. 2010;36(4):659-64.

17. Han B, Jaurequi J, Tang BW, Nimni ME. Proanthocyanidin: a natural crosslinking reagent for stabilizing collagen matrices. J Biomed Mater Res A. 2003;65(1):118-24.

18. He L, Mu C, Shi J, Zhang Q, Shi B, Lin W. Modification of collagen with a natural cross-linker, procyanidin. Int $\mathrm{J}$ Biol Macromol. 2011;48(2):354-9.

19. Fine AM. Oligomeric proanthocyanidin complexes: history, structure, and phytopharmaceutical applications. Altern Med Rev. 2000;5(2):144-51.

20. Miles CA, Avery NC, Rodin VV, Bailey AJ. The increase in denaturation temperature following cross-linking of collagen is caused by dehydration of the fibres. J Mol Biol. 2005;346(2): $551-6$.

21. De Mello JP, Petereit F, Nahrstedt A. Flavan-3-ols and prodelphinidins from Stryphnodendron adstringens. Phytochemistry. 1996;41(3):807-13.

22. De Mello JP, Petereit F, Nahrstedt A. Prorobinetinidins from Stryphnodendron adstringens. Phytochemistry. 1996;42(3): 857-62.

23. Madhan B, Subramanian V, Rao JR, Nair BU, Ramasami T. Stabilization of collagen using plant polyphenol: role of catechin. Int J Biol Macromol. 2005;37(1-2):47-53.

24. Reddy RR, Phani Kumar BVN, Shanmugam G, Madhan B, Mandal AB. Molecular level insights on collagen-polyphenols interaction using spin-relaxation and saturation transfer difference NMR. J Phys Chem B. 2015;119(44):14076-85.

25. Danilov NA, Ignatieva NYU, Iomdina EM, Semenova AS, Rudenskaya GN, Grokhovskaya TE, Lunin VV. Stabilization of scleral collagen by glycerol aldehyde cross-linking. Biochim Biophys Acta. 2008;1780(5):764-72.

26. Bedran-Russo AK, Castellan CS, Shinohara MS, Hassan L, Antunes A. Characterization of biomodified dentin matrices for potential preventive and reparative therapies. Acta Biomater. 2011;7(4):1735-41.

27. Zhai W, Chang J, Lin K, Wang J, Zhao Q, Sun X. Crosslinking of decellularized porcine heart valve matrix by procyanidins. Biomaterials. 2006;27(19):3684-90.

28. Slusarewicz P, Zhu K, Hedman T. Kinetic characterization and comparison of various protein crosslinking reagents for matrix modification. J Mater Sci Mater Med. 2010;21(4):1175-81.

29. Bersanetti PA, Bueno TL, Morandim-Giannetti AA, Nogueira RF, Matos JR, Schor P. Characterization of rabbit corneas subjected to stromal stiffening by the açaí extract (Euterpe oleracea). Curr Eye Res. 2016;9:1-6. 